\title{
The Effect of Factors of Climate Resilience of Residential Houses on Reducing Energy Consumption
}

\author{
Nasim Zahraeipoor \\ Graduate Student in Architecture, \\ Varamin, Tehran
}

\begin{abstract}
Nowadays, lack of balance between architecture and the environment has caused unpleasant effects and environmental impacts, like environmental pollution, reduced natural resources, climatic changes, and an ever-increasing decline in energy sources. Thus, designers and architects try to find the right solutions for designing environmentally compatible constructions. Here, unsuitable climatic conditions, especially the drying out of the Zayandehrud River (due to the increase in the temperature of the planet) have forced architects and planners to focus on climatic problems.

The purpose of the study was to know how to use architecture primarily as a tool for achieving a plan to reduce energy consumption. Accordingly, the basic principles of native architecture were used for this purpose.

The method was based on causal research and simulation. The tool used were Design Builder thermal simulator software. An example of a contemporary home was simulated in this software, and its thermal behavior was analyzed and compared.

The energy consumption of a contemporary home was approximately 3.5 times that of a home with sustainability factors, whereas its area is almost twice as the home with sustainability factors. However, the percentage of optimal openings indicates its effect on energy consumption. This is because the higher percentage (more than $40 \%$ ) is by no means a reason to be good (other factors are effective too). That the optimal percentage of opening can have a significant effect on the internal energy consumption, which reduces the energy consumption of the home with sustainability factors despite smaller area, its proper opening percentage has made it more suitable and more attractive than the contemporary home.
\end{abstract}

Keywords: Sustainability, Energy Consumption, Climate, Residential Homes

\section{INTRODUCTION}

One of the most important and critical problems in architecture is sustainability and design in an environmentally compatible way. Environmental sustainability cannot be achieved except by organizing human activities and changing their way of thinking so that natural resources are preserved for the future (Rashidi, 2010). Sustainable architecture has a mixture of cognitive, environmental, social, political and ethical values. More reflection on the principles of traditional architecture show that the concept of sustainability is rooted in old customs and ancient cultures and shown in traditional life in the form of reverence for nature and natural resources. Creating harmony with nature, the establishment of a responsive plan and the needs of residents have always been the base of the

\author{
Mohammadmehdi Danesh \\ Department of Architecture, \\ Texas A\&M University \\ Danesh@tamu.edu
}

work of architects (Amjad and Sastari, 2011). The concept of climate design is not a new idea. Human has always sought to create conditions for his comfort and well-being throughout the history, so his experience has always been the solution to him throughout the course of life. These options can be effective in reducing environmental damage by being compatible with today's technology (Vasig \& Bemanian, 2008). Today's architecture is in a state where the use of traditional architectural patterns, as used in the past, is not possible. This is because today, issues such as population growth, land scarcity and so on are among our concerns. The formation of this model lies in the concept that the use of these concepts can create a valuable architectural effect and meet needs. One of these needs is reducing energy consumption using traditional architectural patterns.

Nowadays, the imbalance between architecture and the environment has caused unpleasant effects and environmental impacts, like environmental pollution, reduced natural resources, climate change, and an everincreasing decline in energy sources. From this, designers and architects try to find the right solutions for designing environmentally compatible constructions. One of the most effective one of these solutions is sustainability issues in architecture that tackle issues like environmental impact of buildings, green buildings, design for recycling (Izadyari, 2011). Scientists believe that the use of clean and renewable energy instead of fossil fuels and energy and running the principles of environmental sustainability can reduce environmental pollution, among which architectural spaces are one of the widespread human areas. They can play an important role in the process of environmental protection. In contemporary architecture, with the growing growth of construction, attention to the sustainability and sustainability criteria has gained more credit. The phenomenon of global warming and the problem of environmental pollution are considered the major humanitarian issues around the world, whereas the role of the building sector in developing these problems is accelerating. This has pushed the construction industry to move towards sustainable development. In general, the concepts of sustainable development are presented in three areas: environmental sustainability, economic sustainability and social sustainability (Ghorbani, 2011). 
"Sustainable architecture is an inclusive phenomenon, not like the tendency to focus on diminishing the use of energy and materials. It involves attitudes like: technology architecture, green architecture, smart architecture as well as environmental design, behavior-oriented architecture, economics-based architecture, and so on. Thus, it distinguishes itself from previous architectures that followed the function or creation of a pure form." (Ahmadi, 2003) Moreover, one cane, based on the definition of Dr. Mohammad Reza Jodat "Sustainable architecture is a kind of architecture respected for its existence. Sustainability can be perceived as a model where available materials and resources are used more efficiently than being wasted or neglected." (Jodat, 2013)

If the figure below is considered based on a color spectrum, the darker the color is, the more stable it is, and the more it tends towards white, the more normal building it is. Sustainability is a threshold where utilization of building resources and land-based waste production is in equilibrium. These are the buildings that can be sustained in three areas: social, economic, and environmental.

The green building is a route between ordinary buildings and sustainable buildings to achieve sustainable construction. This path is shown schematically by bright green to dark green.

Green architecture is divided into 15 categories that have their own specialized fields, including Table (1), and the cases that are very necessary by the designer are shown by dark color.

Table 1: 15 basic designs of green architecture (El Feky, 2006)

\begin{tabular}{|c|c|}
\hline Grouping & Explanation \\
\hline $\begin{array}{l}\text { Sustainable site } \\
\text { design }\end{array}$ & $\begin{array}{l}\text { Includes site selection, landscape design, designing strategies to make the best use of resources with } \\
\text { minimal negative environmental impact }\end{array}$ \\
\hline $\begin{array}{l}\text { High energy } \\
\text { efficiency }\end{array}$ & 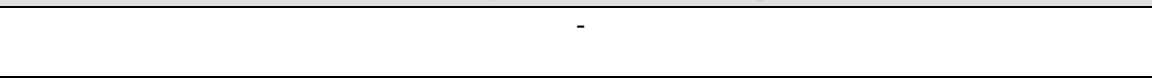 \\
\hline Rain water & - \\
\hline $\begin{array}{l}\text { Utilization of sewage } \\
\text { water }\end{array}$ & - \\
\hline $\begin{array}{c}\text { High energy } \\
\text { efficiency }\end{array}$ & - \\
\hline Contamination & - \\
\hline $\begin{array}{c}\text { Safeguarding } \\
\text { materials }\end{array}$ & - \\
\hline Maintain resources & - \\
\hline Energy preservation & $\begin{array}{l}\text { This area seeks to reduce the use of non-renewable energy in the environment, especially the sources } \\
\text { that pollute the local and regional scale, using renewable energy with the least impact on the } \\
\text { environment, reducing the energy consumption of buildings, the use of renewable energy And prevent } \\
\text { the destruction of the ozone layer }\end{array}$ \\
\hline $\begin{array}{l}\text { Improving inner air } \\
\text { quality }\end{array}$ & C \\
\hline $\begin{array}{l}\text { Improving residents' } \\
\text { satisfaction }\end{array}$ & $\begin{array}{l}\text { The interior features of the building can be designed so that provide residents with satisfaction. These } \\
\text { include thermal comfort, visual comfort, sound }\end{array}$ \\
\hline Innovation & 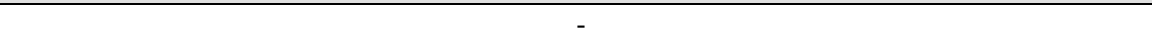 \\
\hline $\begin{array}{l}\text { Wasting and toxic } \\
\text { substances }\end{array}$ & - \\
\hline Transportation & - \\
\hline Eco-friendly property & - \\
\hline
\end{tabular}

Sustainable design for humans and shaping the building form according to the environmental and internal environmental systems within the building provide users with a level of internal conditions that is acceptable to them. At the same time, it simultaneously consumes low energy consumption (fossil fuels). Among the key elements in the bio-design are energy and how much energy is used to achieve comfort conditions. Clearly, lower consumer comfort conditions are below design standards (e.g. one degree higher or lower than ASHRAE Standards), where the lower the standards are, the lower the total energy consumption: comfort temperature is usually between $18^{\circ}$ $\mathrm{C}\left(85^{\circ} \mathrm{F}\right)$ and $24^{\circ} \mathrm{C}\left(75^{\circ} \mathrm{F}\right)$. However, this temperature is temporary and depends on relative humidity, which should be between $30 \%$ and $65 \%$. In general, one can state that high relative humidity requires a low air temperature that humans feel comfortable with (Lekner, 2013). Thermal comfort is not confined to the temperature and temperature spectrum, radiant temperature, air flow and vapor pressure, but on the coverage of the inhabitants ${ }^{1}$ and the number of occupants and their activity. Simultaneously, the designer solves the spatial and frontier needs of the building and selects its components and components for use, it should be considered in relation to the technologies and operating systems. The final option is to determine the goal of improving external shell structure and to develop the use of static strategies to optimize internal comfort conditions that can reduce energy consumption and demand for electricity and fossil fuels. Inactive design uses simple cooling and heating techniques to provide the indoor temperature of the building to change it using natural resources in the environment. The first is to identify a range of inactive choices and systems according to local climates. Radiation, air and wind temperatures are 
based on topography and the surrounding area and the effect of urban areas and the design of artistic environments. The main approach is not only architectural design and architecture to follow the region's climate, but also to respond to that climate. The climate does not determine the shape of the building yet affects it. The first principle is to prioritize the deployment of passive systems on active systems as the best way to achieve a bio-design is ideal. This design depends on the latitude and location of the site. The main strategies in this system are the proper formation of the building dependent on the direction of the region's sun, the use of natural ventilation, vegetation, and shading (Watson, 2011). The choice of building materials has an effect on the environmental impact on the building itself. Building materials are processed before use in the building and partly by them. For instance, in Britain it is estimated that building materials will account for about one tenth of energy consumption and carbon dioxide emissions, which is a high figure. When selecting materials, several factors must be taken into consideration, and it is unlikely that absolute rules can be applied to all conditions. In this context, the first question is how should environmental impacts be assessed? What is the environmental impact assessment factor? This can be seen as factors determined by the inherent properties of the material and as factors affecting it in design. Table 2 shows the quality and factors influencing material analysis:

Table 2: How to deal with materials in designing (Resource: Writer)

\begin{tabular}{|l|}
\hline The factors determining the quality of the material are: \\
\hline Energy needed for material production \\
\hline Carbon dioxide emissions from the production of materials \\
\hline Environmental impacts due to extraction of materials (mines, wood from forests, oil, and so on) \\
\hline Material toxicity \\
\hline Transportation of materials from the place of production to the place of consumption \\
\hline The amount of contamination of materials after the expiration of their useful life \\
\hline The factors influencing the choice of materials and design decisions are: \\
\hline Location and Details of Architectural Elements \\
\hline Maintenance required and materials for maintenance and maintenance \\
\hline Utilizing materials that reduce the environmental impact of other elements (e.g. insulation) \\
\hline Design flexibility instead of changing over time \\
\hline Longevity of the materials and its potential for reuse if the building is damaged \\
\hline
\end{tabular}

Perhaps one can say that the most important index of the environmental impact of an object is its "latent energy." The latent energy is describing the energy used to produce an object. The latent energy can be checked in a brick as well as in the whole building. The resulting energy is a very important index of the amount of non-renewable energy that is the main cause of environmental degradation (Dadson, et al., 2011). It should be noted that the study of the building materials and the hidden energy is very difficult and time consuming and there are many specialists in this field. However, in the early stages of designing, considering some general principles, in part, the choice of materials (the more natural the materials are, the low energy it is) was to reduce energy consumption. The practical methods of designing the inactive system are the correct encounter with the following chapters. As shown in Table 3, the correct implementation of each item will improve and enhance the sustainability of each architectural structure:

Table 3: Physical design indices for achieving static design (Resource: Writer)

\begin{tabular}{|c|c|}
\hline Required cases for designing the body & Explanations \\
\hline Configuring and designing the form & $\begin{array}{l}\text { The form of the building consists of the organization of the space and its design, based on its } \\
\text { structure in relation to the environmental energy and climate data of the region as a response } \\
\text { to the inactive system. However, reducing the building's heating equipment by optimizing } \\
\text { the heat input is not just a matter of building orientation. }\end{array}$ \\
\hline Orientation & $\begin{array}{l}\text { In this strategy, one should be aware of the shape of the building, the underlying position and } \\
\text { location of the site and its orientation towards the sun and the direction of the wind. In most } \\
\text { regions, a rectangular shape along the east and west is designed to reduce sunlight, which is } \\
\text { why it is a huge part of the heat absorption by the entrance of the windows. }\end{array}$ \\
\hline $\begin{array}{c}\text { Integrated design - Flexibility and permeability (including size } \\
\text { and position of openings) }\end{array}$ & The building's permeability to light, heat, air and the possibility of change \\
\hline Sun control tools & $\begin{array}{l}\text { Shadows, louvers, colored glasses and reflectors should be placed on the front of the } \\
\text { building, which is always warm, depending on the latitude. The right form of the shadows is } \\
\text { to have the highest density on warm days. The use of intelligent views that are based on the } \\
\text { sun's rotation angle, sunlight, and outside air open or closed, are used in most applications. }\end{array}$ \\
\hline Natural ventilation & $\begin{array}{l}\text { The best way to achieve inner comfort is to promote it. To use this, you need to know the } \\
\text { forces on the site. The wind is the most important resource available on the site, which } \\
\text { should be recognized by optimizing the local wind conditions throughout the year and time } \\
\text { each day. }\end{array}$ \\
\hline Landscape design & $\begin{array}{l}\text { Studies have proven that visual comfort and well-being through plants are well defined. } \\
\text { Another benefit is the physical improvement of physical air quality. The bio-design needs to } \\
\text { bring more nature into the artifact. The artificial environment needs to be opened up against } \\
\text { diverse and rich nature. }\end{array}$ \\
\hline Building mass & $\begin{array}{l}\text { This item is used for direct engagement in the building and in the face to the south, depends } \\
\text { on the designer's accuracy in familiarizing himself with the direction of the sun's movement } \\
\text { on the site, the shadow of the building and other buildings, and features on the site. }\end{array}$ \\
\hline
\end{tabular}




\section{METHODOLOGY}

The method used to work is generally divided into two main parts, both complementary. If we use the method as a way of determining the trend and direction of research, the initial method is to examine the design examples, because we assumed that to achieve a sustainable design, we need to have a more radical look at traditional architecture and see the vision from the beginning, refer to research principles and provide sustainable design methods with the aim of extracting and consolidating the research framework. The second part is simulation. In fact, the general method is the type of theory and its acceptance as a proper method according to traditional architectural records. In the second method, the simulation method is used to achieve the practical results of energy consumption reduction in hot climate.

As the purpose of this design is to achieve a sustainable design in terms of energy and cost using design and architectural-climatic principles, then the research consists of a combination of qualitative and quantitative methods like that of case-related. It tries to explain them by showing the strong relationship between the variables without the need to prove that the variable is the cause of the emergence of another variable (Groat et al., 2008), and the replication research, based on the research that a condition can be identified by rebuilding it in an alternative environment. The tools for achieving the goal are using the existing information, documents, viewing (field impressions), library studies, and simulation methods with Design Builder software.

Simulation in this study was done using the Design Builder software, which is a utility for thermal analysis of buildings that measures the effect of environmental factors on the building. The capabilities of this software are calculating the total energy consumption of the building, calculating the cooling and heating load of buildings, illustrating solar radiation on windows and other surfaces, calculating daylight factors and showing the position of the sun and the direction of the sun relative to the model in each day and hour. This software can calculate the energy consumed in hours, days, months and years according to the climatic information and help the design team to take design decisions based on actual information. The credibility of the Design Builder software is proven in numerous previous studies. By referring to the main page of this software site, one can see that in England's decision-making bodies, the results of the simulations are completely valid and recognized by introducing the characteristics and climate data of different regions (Design Builder, 2010).

By using the Design Builder software, a home is simulated with a sustainability factor and then analyzed for energy consumption and compared to the results obtained from the simulation of a typical home to reduce energy consumption derived using traditional architectural patterns.

\section{REDUCING ENERGY CONSUMPTION IN THE BUILDING USING CLIMATE DESIGN}

The first stage in climate design is climate recognition, and the second phase how it is exploited. For a building that provides residents with comfort and is efficient in terms of energy efficiency and recognizing the climate and the factors affecting it are among the essential requirements (Qisbaklu, 2013). As mentioned from the beginning, the goal is to respond to the question of how much architectural design and appropriate selection of traditional architecture factors can reduce the energy consumption of buildings? First, architectural and urban factors affecting energy consumption in buildings can be named, and depending on the importance and magnitude of the power, one can look for a precise answer to each of these factors. These are the orientation and elongation of the building, the window size at different fronts, the type and size of the canopy, the layout of the interior, the number of floors, the type of roof and the height of the floor relative to the ground.

Rural and traditional buildings have provided the right solutions for climate issues (Kasmaei, 2010), then solutions can be found in these buildings, and even seek to prove that in addition to preserving these elements in energy efficiency in other cases and stages of Iranian design to identify the cities used. Two methods are suggested to reach the desired goal. Utilizing the principles of climate design and the second method of comparative comparisons of these principles with the existing situation through the simulation of Design Builder software, which can finally be achieved consistently. The city weather data was extracted from the beginning of 1992 to the beginning of 2003 in the 10-year period, and entered as the Energy Plus file in Design Builder software. According to Figure 1, urban climate information is shown in hot climate (Internet Page of Energy Efficiency and Renewable Energy, 2015). 


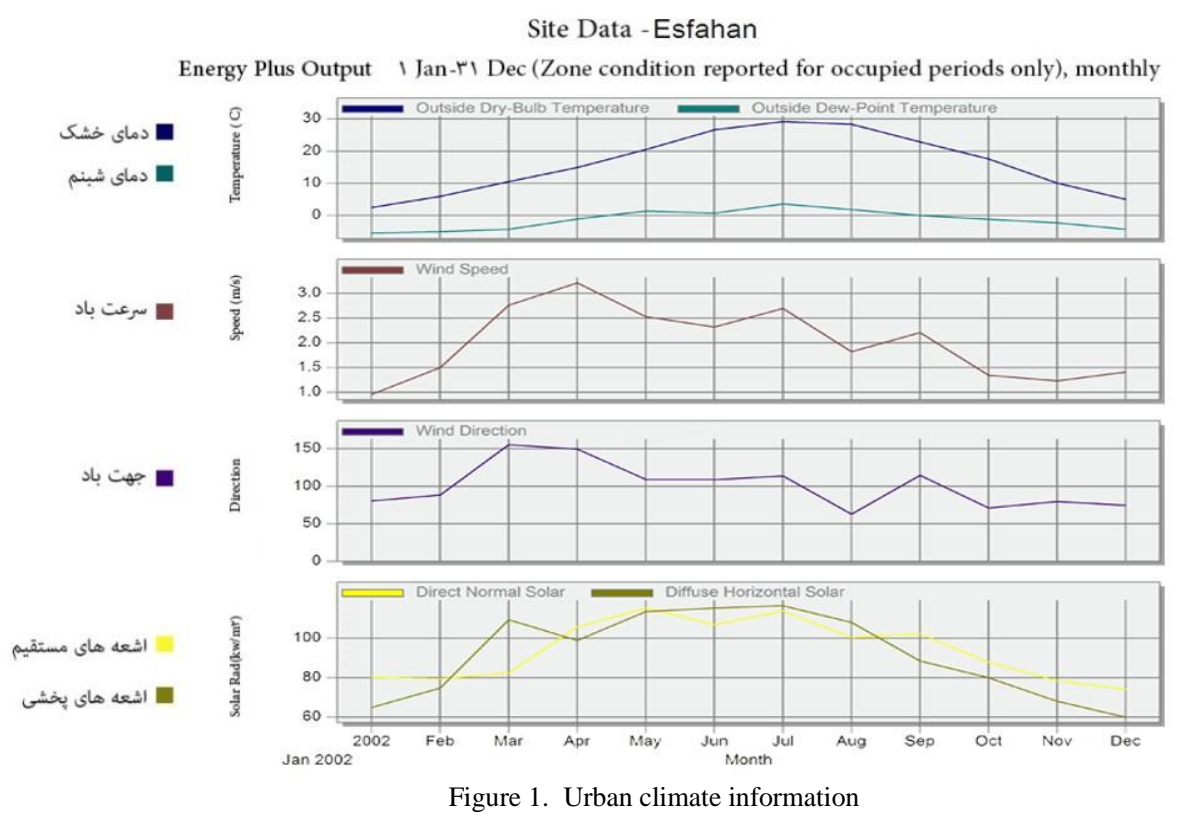

\section{THE SAMPLES STUDIED A HOME WITH SUSTAINABILITY FACTORS}

The architectural spaces of this house are made of persistence elements on four sides of the square courtyard. The southern side looks higher than the other side. The eastern side has spaces such as a hallway with an arched entrance to the Orsiye side room with three doors overlooking the courtyard and two verandahs on the sides of the hall. The western side is related to the orientation of the eastern side, with the difference between the western side of
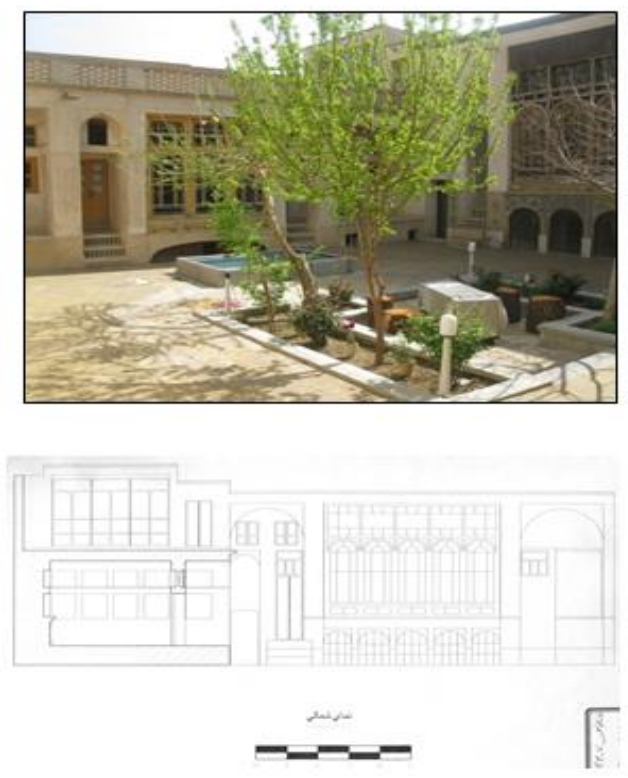

the five doors in the middle and the two rooms of the three doors, the sides are faced with four stucco columns.

The northern side has three rooms with flat dimensions and flat roofs. On the second floor of the second floor, on the other side of the two rooms, as well as on the space of the alley adjacent to the house, there is a hall with a few facades. The western side room is a terrace with three lanyards with colored glass and drawings of lion and sugar, and wall-mounted stucco.
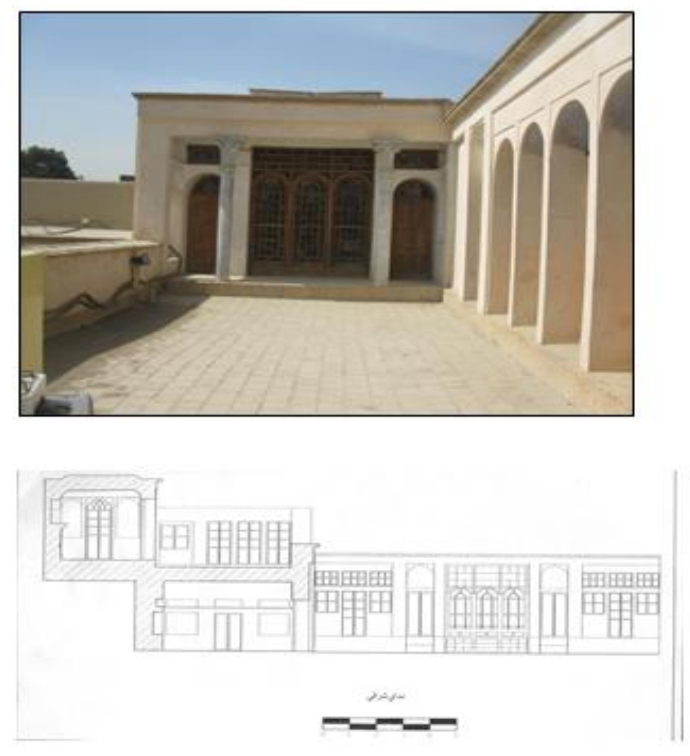

Figure 2. The samples studied a home

Simulation of the buildings in the relevant software is a solution by which it is possible to examine more accurately and estimate the conditions and potentials necessary to evaluate their impact on reducing the open cooling and heating. These factors can be summarized according to the proportions, orientation, and the ratio of the uplink to the surface to the south. Design simulator engine, Design builder 2.5, and Energy Plus provide simulations in an intuitive environment, so the results can be presented both numerically and graphically. 


\section{SOFTWARE ASSUMPTIONS}

The correct simulation is needed to reach the correct results with any software and virtual environment. This means approaching an unreal environment, which also involves providing correct definitions of the variables required in the software. In doing so, it is necessary to determine some of the assumptions in the software intended to achieve the intended results.

The materials are classified into two categories of roofing materials and wall materials, which tried to use as much material as possible in the virtual environment (brick, lime sand mortar) to be used for simulation.

The structure was raw bricks wall, and later in the bricks. In some houses, wooden beams were designed as horizontal floats in the hollow section or higher, designed to withstand the strength of the structure against earthquake.

The ceiling was a wooden beam with wooden beams and paving stones, plastered interior lining and a flat roof covering of straw. In late Qajar, the roof ceiling was used in addition to the metal skeleton structure as the final cover.

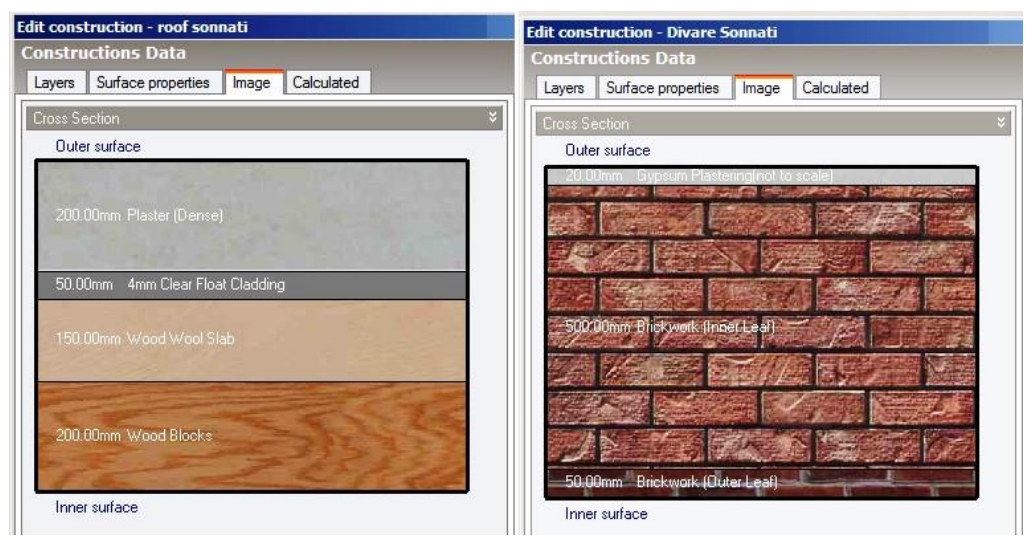

Figure 3 Roof and Wall Layers

It should be noted that due to the large amount of input information to the simulation software, it is related to the cold season. Thus, the winter portion of this house is simulated with sustainability factors.

\section{ANALYSIS OF HOME RESULTS WITH SUSTAINABILITY FACTORS}

Considering the results of the simulations, it is primarily known that the air temperature in the non-use of thermal equipment is always outside the comfort zone. Thus, for reaching the comfort, one needs to use the heating equipment. The minimum internal temperature is also -6.74 degrees average, and the most heat dissipation is from the seams is the rooms (2.27 kilowatt-hours). However, the direct absorption of the sun is $0.93 \mathrm{kWh}$ through the walls and openings.

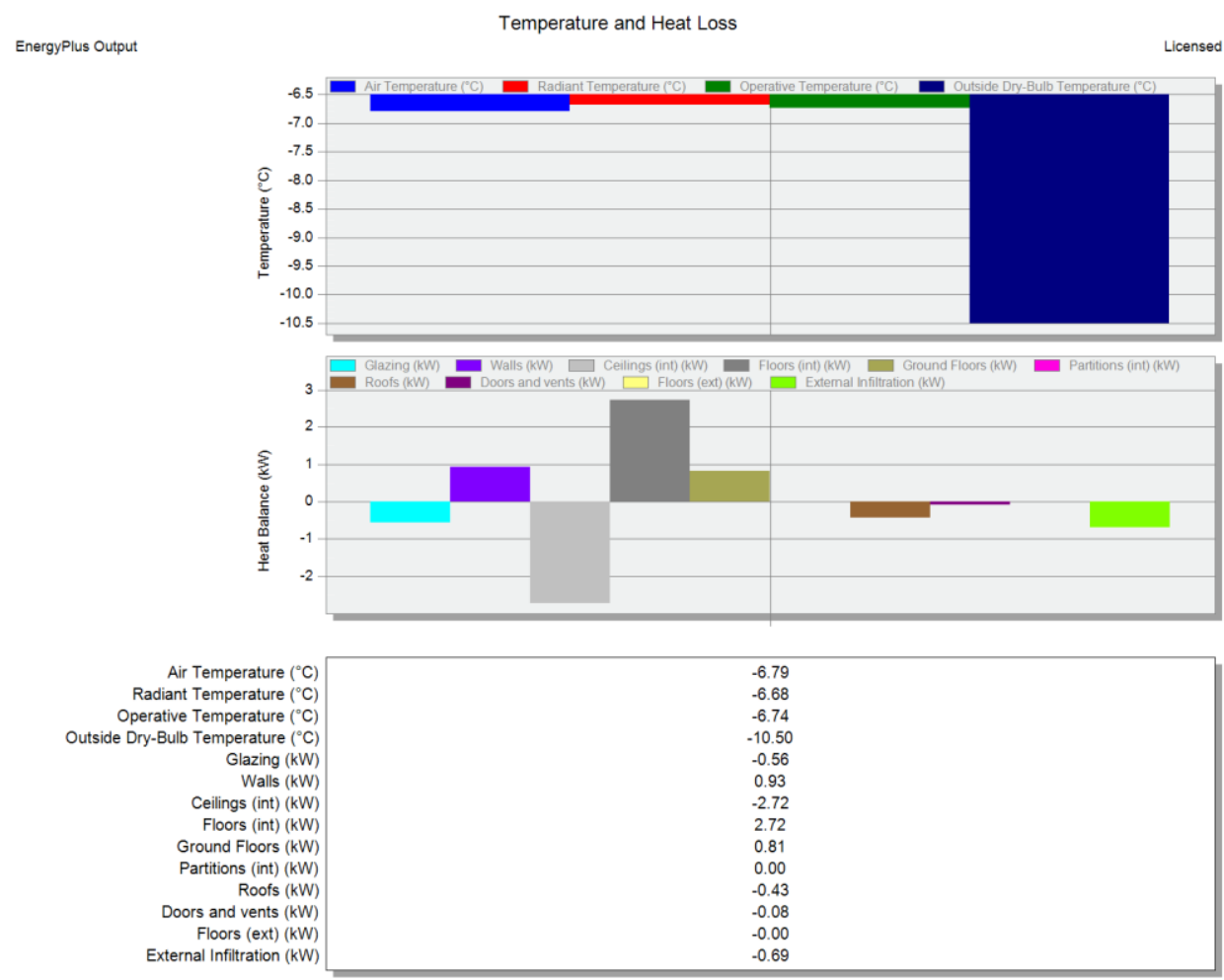

Figure 4: Analysis of home results with sustainability factors 
In Figure 4 , it is clear that the waste is greater than what is most relevant to the outflow of air from the inside out, the entry of cold air from the outside into the openings, the roof and the ventilation through the doors and seams.
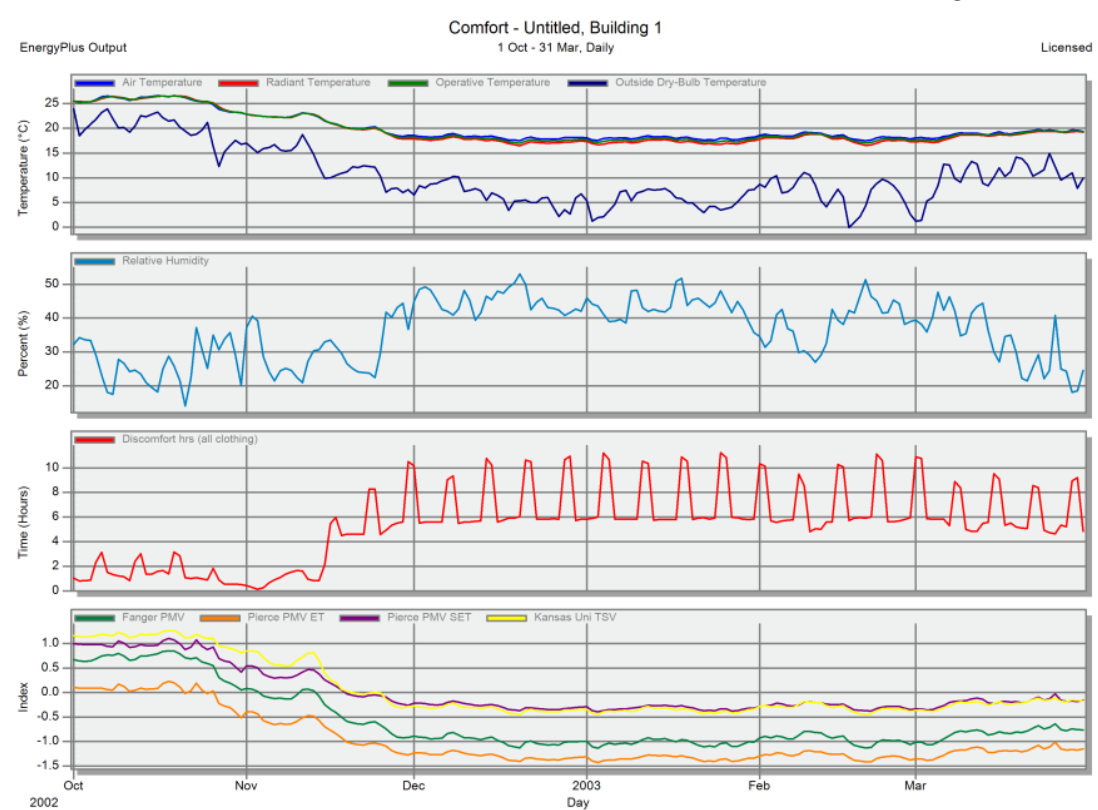

Figure:5 Analysis of home results with sustainability factors

Simulation done shows the amount of energy required to achieve winter comfort in Figure 5. In addition, according to comfort standards, the University of Kansas has the highest standard for indoor conditions, while Fenger and Pierce standards get the lowest levels. Thus, for reaching comfort, we need to use warm clothing to be able to save energy by making it much easier.

According to Figure 6, after the use of thermal equipment, the comfort temperature of the residential unit has reached an average of 20 degrees throughout the year. However, the energy consumption is $11750 \mathrm{kWh}$ per year, which is a high figure. It is also shown in this table that the greatest losses are due to the outflow of air inside the outside due to the low seam and the presence of seam inside the building, including joints (5,000 kilowatt hours). Thus, with little measures such as insulating the window and the doors, one can prevent heat loss a lot every year. It is also clear in this diagram that the amount of generated thermal energy is approximately equal to the amount of absorption that is due to the sun. Therefore, one can use the sun as a potential for design.

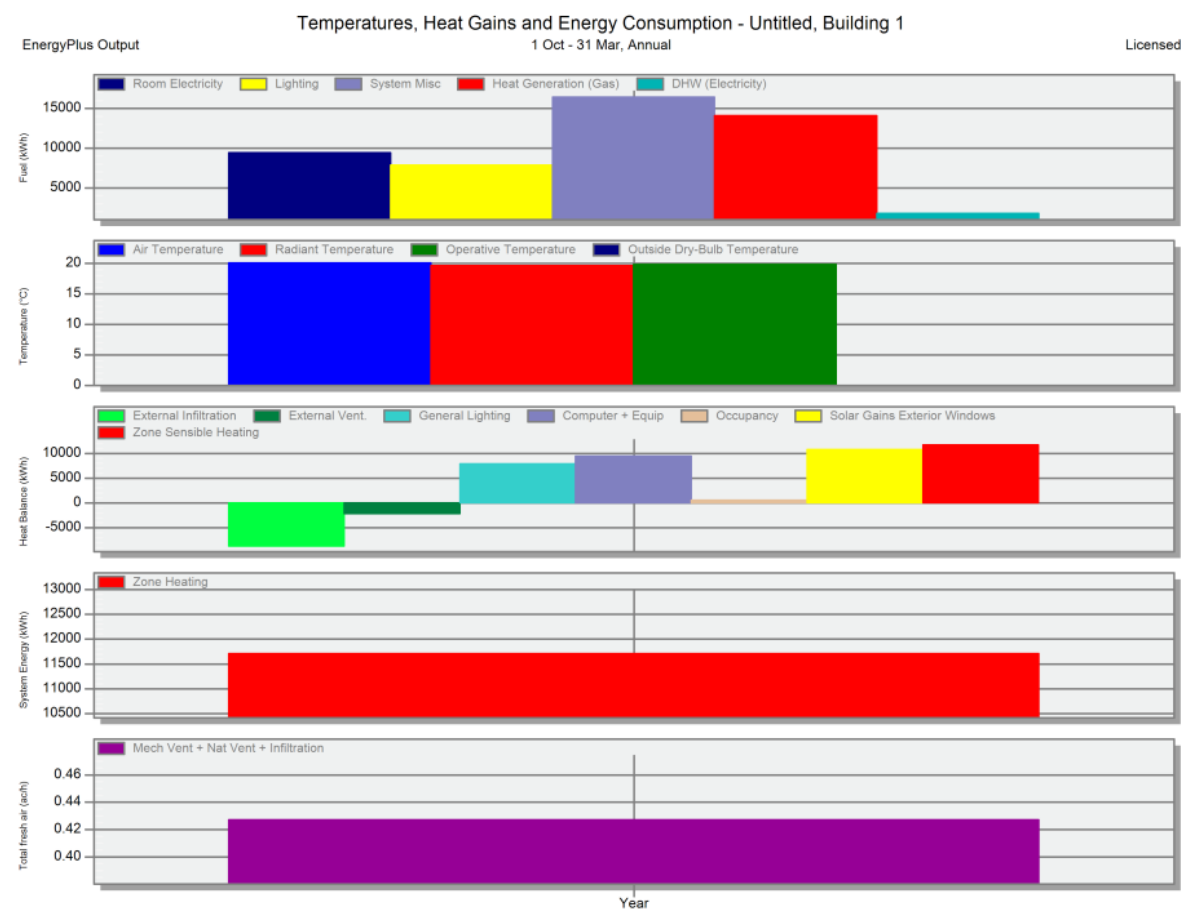

Figure 6: Analysis of home results with sustainability factors 


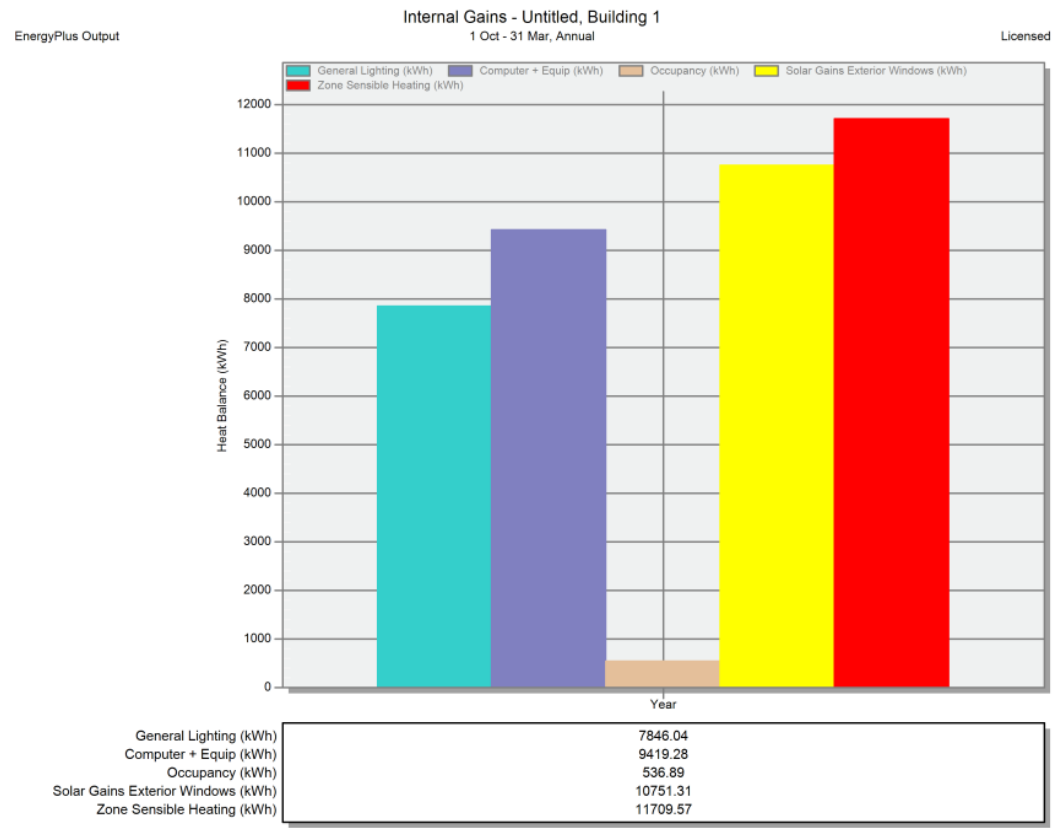

Figure 7: Analysis of home results with sustainability factors

Figure 7 and 8 show the effect of direct absorption and radiation $(10751 \mathrm{~kW} / \mathrm{h})$. Thus, the sun can be regarded as an important factor in design as it is well-known in the table as it increases the absorption and emission of the sun until mid-

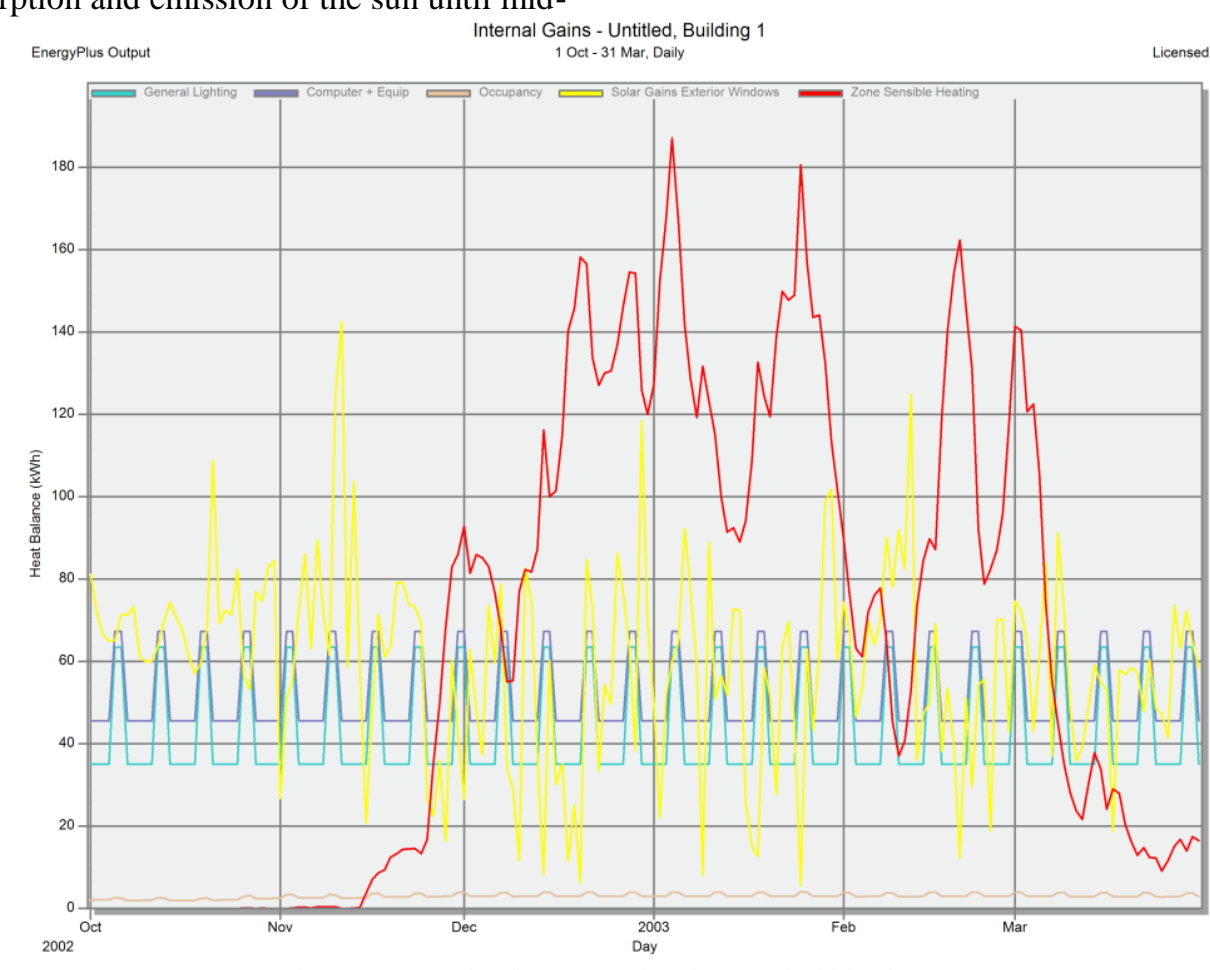

Figure 8: Analysis of home results with sustainability factors

Energyplus outpu Internal Gains - Untitled, Building 1
November. In this chart, the most commonly used figure is that of this month, which is the minimum radiation and absorption this month.

\section{ANALYSIS OF THE RESULTS OF A} CONTEMPORARY HOUSE IN HOT CLIMATE

Considering the simulation results and the above graph, one can easily see that the air temperature inside without the use of heating equipment is, on average, lower than the comfort constituent is and the outside temperature is 3 degrees. In addition, the factors that influence this effect can be assumed the hot air outlet due to direct absorption from the south side and under the influence of seams of connections. The change of air and the condition of the air inside the air cause excessive heat exiting from the sun's absorption. Moreover, the waste from the openings (windows) and roofs, walls and cold air entrances from the outside, have the greatest effect on the internal heat dissipation. 

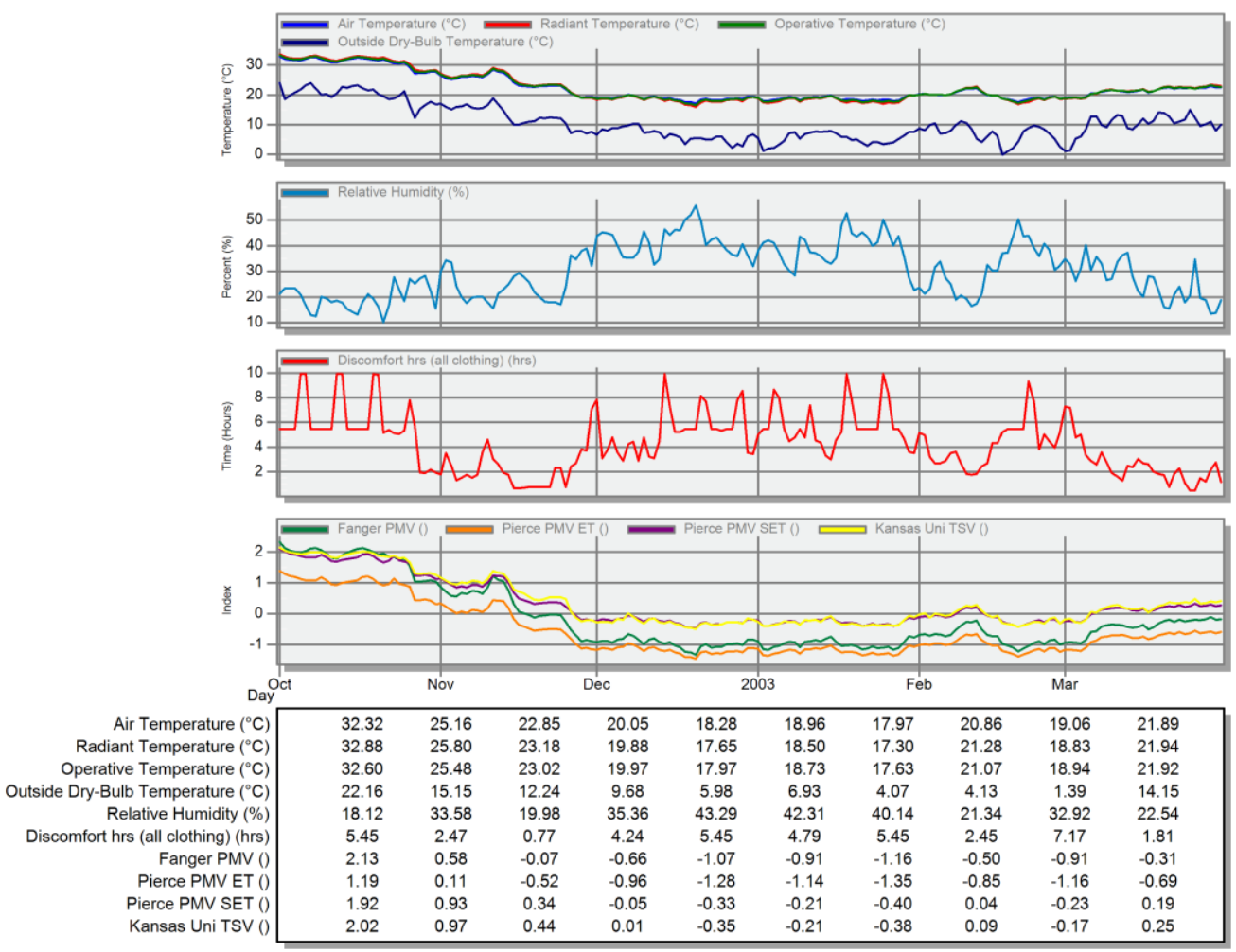

Figure 9: Analysis of home results without sustainability factors

Considering Fig. 9, the results of daily statistics and data during the cold seasons show that the interior space is within the comfort range (18 to 32 degrees Celsius). Considering the standards of comfort and safety, Kansas University and Pierce, the air is getting colder and the comfort zone becomes more limited. According to Fegner standard, which is also called Adaptive Comfort, people can only be fitted with appropriate coverage in this area. In addition, in this standard, PMV is closer to zero, and it is clear from the results that in the end of the month, people with more satisfaction are more likely to be, while in the other months these are negative amounts due to the cold, and that the maximum dissatisfaction is in February. In this chart, it is clear how the heating equipment consumes the most and least of the year. First, it is turning on the heating devices from the very beginning of the cold season, and the highest consumption is in February. In addition, on the comfort time table, the maximum hours that are not comfortable is an average of 10 hours a day, even lowered to 2 hours a day late in March (on average).

In Figure 10, the total energy consumed inside the building can be seen; the required thermal energy is needed is 3357 $\mathrm{kWh}$. It is also interesting to note that the percentage of the building's openings is $36 \%$ on the south side, while the absorption of heat from the sun is $1,7052 \mathrm{kV}$ per hour, which is a high value of about 5 times the amount of energy that can be used for heating. Therefore, first, the proportion of $30-36 \%$ for the southern side can be suitable and the only necessary measures are the use of heat, insulating and preventing its loss. 


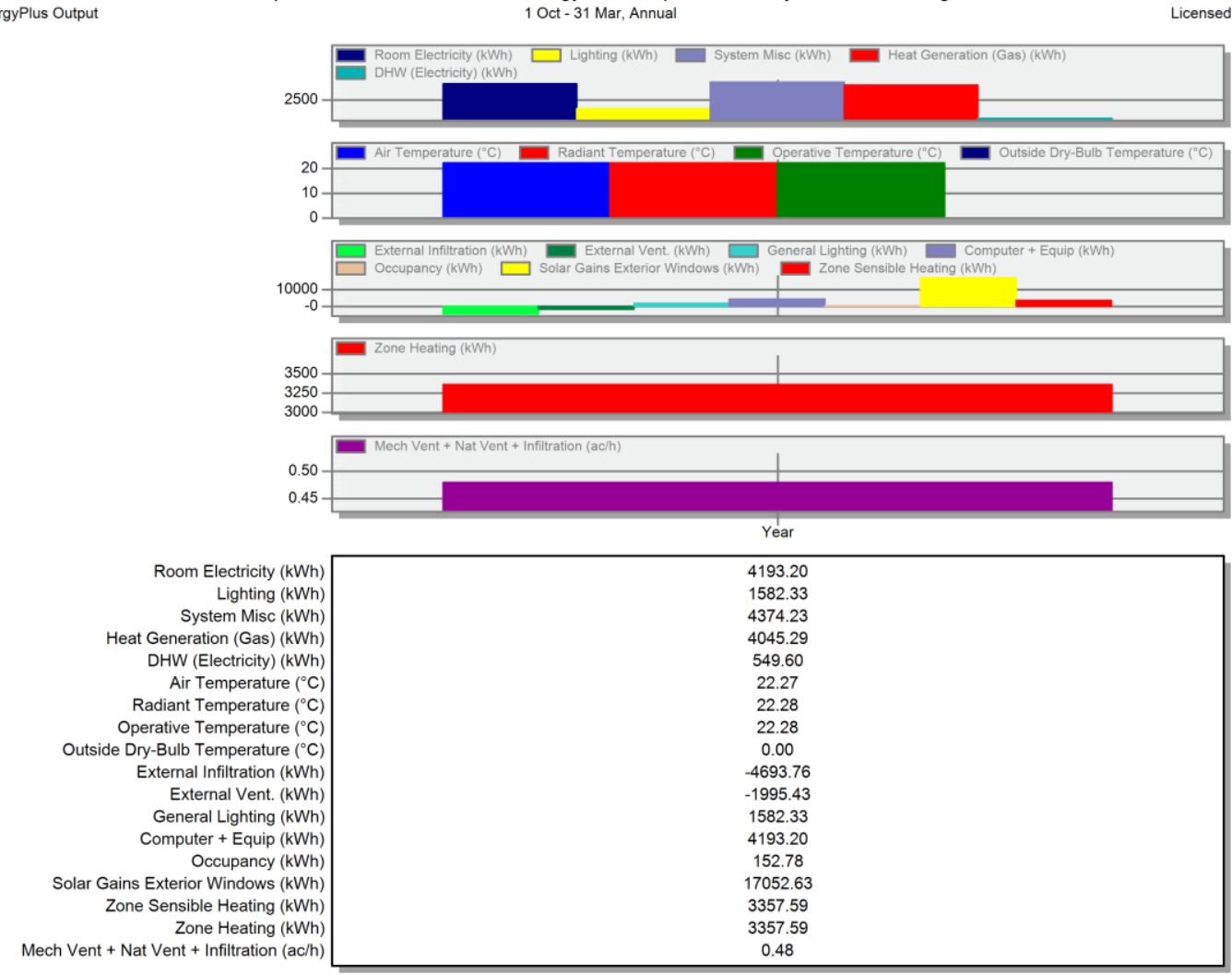

Figure 10: Analysis of home results without sustainability factors

Figure 11 shows daily heat gain during the cold season as well as the effect of the heat sensation it produces. It is easy to see in this table how much this radiation can affect energy consumption, so that the input of solar radiation into the set can from the energy consumption of the cassette equipment, it is possible to use at least the equipment from October to early December., dependent on the right design.

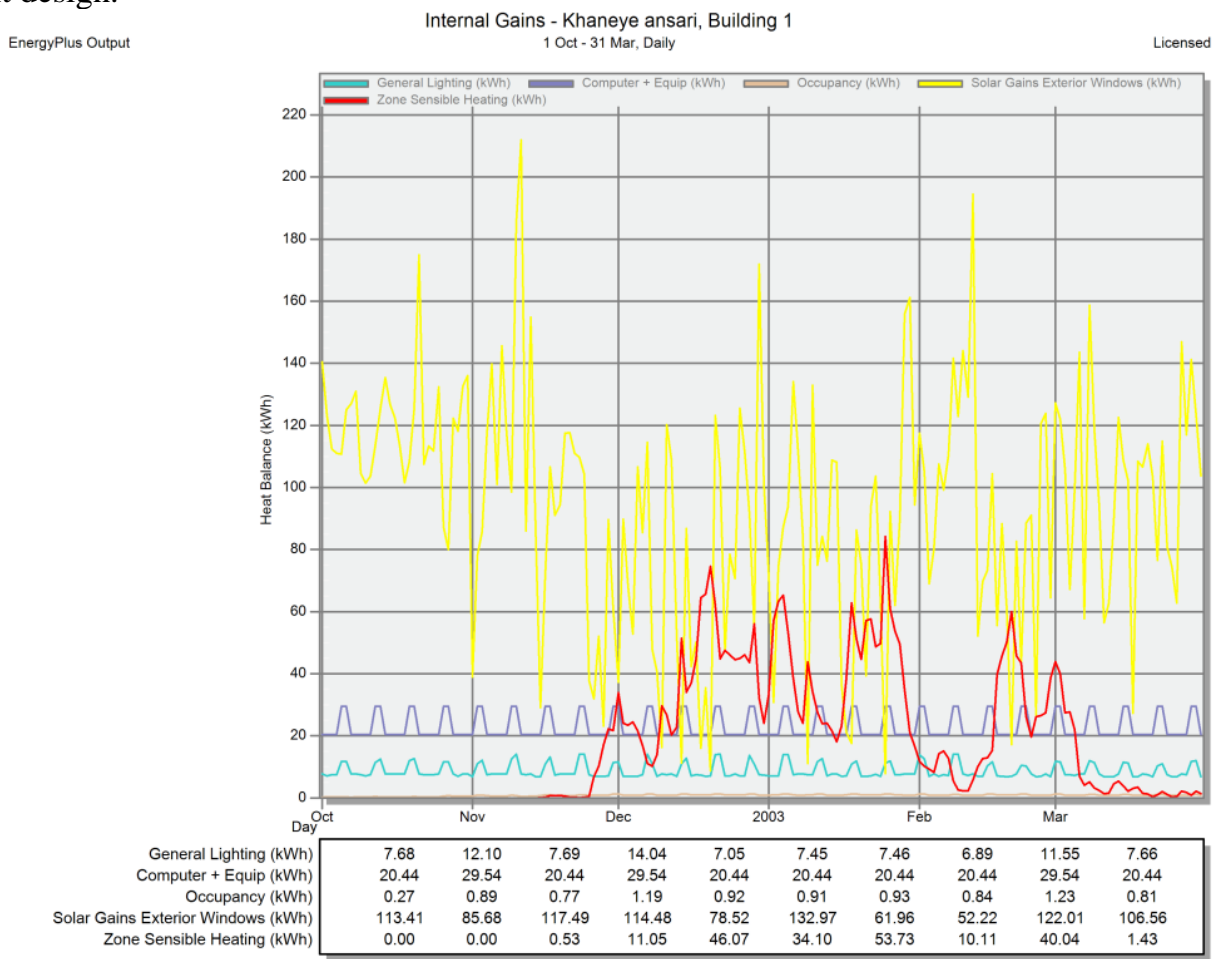

Figure 11: Analysis of home results without sustainability factors 


\section{DISCUSSION}

In comparisons of the two buildings, it can only be mentioned that in the table below the energy consumption, the area of the building and the percentage of openings, to determine how much the consumption depends on these factors.

What can be seen from these two examples is that the energy consumption of a contemporary home is approximately 3.5 times that of a house with sustainability factors, whereas its area is almost twice the size of the home with sustainability factors. However, the percentage of optimal openings indicates its effects on energy consumption, as the higher percentage (up to $40 \%$ ) is by no means a reason to be good (other factors are also effective). The optimal upgrade percentage can have a significant effect on the internal energy consumption, reducing the energy consumption of the home with sustainability factors. However, the smaller the area is, the proper opening percentage, has made it more suitable and more attractive than the contemporary home. What matters is the correct insulation. The research has shown that $50 \%$ can be energy efficient if the insulation is done well. It also includes the general principles that can be used in this area. Sealing as the second principle (after insulation) to prevent internal heat dissipation, and attention to solar design, especially the direct absorption of sunlight in the winter, emphasis on the southern side (the proposed percentage of openings is 30$40 \%$ for optimal radiation in winter). However, it can help reduce the energy consumption by covering the house in the cold season (the coefficient of coating 1.1-1.3).

\section{CONCLUSION}

By pass of time and the change in lifestyle, human needs also change. While our traditional architecture is rich in value architecture, in the contemporary era, imitation of traditional architecture is not feasible, and only meaningful concepts can be derived. The benefits of the design are to be considered. For example, creating a pre-space in the internal entrance of a residential unit, one can use vestibule as the pivot to create the space between the outside and the interior spaces to reduce the heat exchange. Thus, in this study, we compared a traditional home and a contemporary house in terms of thermal behavior, the results of which are briefly summarized in Table 4. Given the widespread data, input into simulation software is for the cold season only. Hence, the winter part of the home is simulated with sustainability factors.

Table 4: Results of the consumption and absorption of two houses by persistence and contemporary home (Writer)

\begin{tabular}{|c|c|c|c|c|}
\hline Home & $\begin{array}{c}\text { the energy } \\
\text { consumption }\end{array}$ & $\begin{array}{c}\text { Building } \\
\text { area }\end{array}$ & Openings ratio & $\begin{array}{c}\text { Sun absorption and effective on } \\
\text { heat sensation }(\mathrm{kw} / \mathrm{h})\end{array}$ \\
\hline $\begin{array}{c}\text { House with } \\
\text { sustainability Factors }\end{array}$ & 3350 & 189 & 36 & 17052 \\
\hline Contemporary House & 11750 & 368 & 40 & 10751 \\
\hline
\end{tabular}

As is seen, the energy consumption of a contemporary home is approximately 3.5 times that of a home with sustainability factors, whereas its area is almost twice as high as the home. Hence, by using traditional architectural patterns in contemporary homes, one can help reduce energy consumption. The most important way to reduce the heating load in this study is to optimize the reception of sunrays. It should be noted that writers did not consider the effect of wall materials on reducing energy consumption. Given the thickness of the walls in traditional buildings and the weak insulation in contemporary buildings, we will have a lower reduction in energy consumption in traditional buildings.

\section{REFERENCES \\ مراجع}

[1] Pariafsai, Fatemeh. "Effectiveness of a Virtual Project-Based Simulation Game in Construction Education." International Journal of Scientific Research in Science, Engineering and Technology (IJSRSET) 2.5 (2016): 377-393.

[2] Zohreh Karami, Mohammadmehdi Danesh, "Developing A WebBased Application for Accelerating Data Management : Construction Materials Section ", International Journal of Scientific Research in Science, Engineering and Technology(IJSRSET), Print ISSN : 23951990, Online ISSN : 2394-4099, Volume 4, Issue 1, pp.152-157, January-February-2018.

[3] Escamilla, E., and M. Ostadalimakhmalbaf. "Capacity Building for Sustainable Workforce in the Construction Industry." The Professional Constructor 41.1 (2016): 51-71.

[4] El Feky Ahmed Toward Applicable Green Architecture an Approch to Colonize the Desert Egypt, Thesis of Phd [Book]. - Eindhoven : Technische Universiteit Eindhoven, 2006. - pp. 12-48.
[5] Mehdizadeh, Saradj Fatemeh, Mohammad Mehdi Danesh, And Hanieh Sanayeayan. "The Effects Of Inner And Outer Layers Of Double Glazed Facade On The Rate of Energy Consumption In Official And Educational Buildings (Case Study: Iran University Of Science And Technology)." (2014): 181-190.

[6] Tahersima, M., Ley, T., \& Tikalsky, P. (2017). Hydration Heat in a mass concrete and a thin slab with limestone blended cement. Int. J. Mater. Sci. Eng., 5(2), 79-86

[7] Pariafsai, Fatemeh. "Students' View on Potential of a Project-Based Simulation Game for Construction Education." (2016).

[8] Dadson A.C., Allen T. F. and Dodson S. I. Ecology [Journal] // University Press. - New york: University Press Oxford, 2011. - pp. $12-33$

[9] Groat, L., Wang, D., (2013). Architectural Research methods. John Wiley \& Sons.

[10] DesignBuilder, (2010). DesignBuilder SBEM Approval, Available in: http://www.designbuilder.co.uk/content/view/112/175/, [Accessed date: $21 / 05 / 2015$

[11] Pariafsai, Fatemeh. "Strengths \& Weaknesses of a Project-Based Simulation Game as an Educational Tool." (2016). www.architects.ir/userFiles/File 534_1.pdf

[12] Tahersima, M., Tikalsky, P., \& Revankar, R. (2018). An experimental study on using a mass radiant floor with geothermal system as thermal battery of the building. Building and Environment.

[13] Pariafsai, Fatemeh. "A review of design considerations in glass buildings." Frontiers of Architectural Research 5.2 (2016): 171-193.

[14] Tahersima, M. (2017). Modeling Heat Transfer in Mass Concrete Floors with Radiant Heat from Ground Source Systems (Doctoral dissertation, Oklahoma State University).

[15] Tahersima, M., \& Tikalsky, P. (2017). Finite element modeling of hydration heat in a concrete slab-on-grade floor with limestone blended cement. Construction and Building Materials, 154, 44-50.

[16] Internet Page of Energy Efficiency and Renewable Energy, http://apps1.eere. energy.gov/buildings/energyplus/cfm/weather data3.cfm/. [ access date: 15/5/2015] 